Brit. Heart F., 1969, 31, 306.

\title{
Electrocardiogram of the Social Drinker in Perth, Western Australia
}

\author{
O. B. TOFLER, B. M. SAKER*, K. A. ROLLO, M. J. BURVILL^, AND \\ N. STENHOUSE $†$ \\ From the Department of Cardiology, Royal Perth Hospital, Perth, Western Australia
}

As part of a study of the "social" drinker and his medical and socio-economic problems, a project was undertaken to observe any relation between cardiovascular abnormalities and drinking habits in a group of apparently healthy men. By including only those men who were well and working, it was intended to minimize the influence of inadequate diet and poor living standards, factors which are associated with the chronic "alcoholic".

\section{SubJeCtS AND METHOdS}

Initially these subjects were obtained by seeing at random a number of hotel managers in the Perth metropolitan area and asking them to volunteer. In turn these men asked their friends, colleagues, and business associates to take part. To be accepted for the study they had to be fully employed men who considered themselves healthy, particularly with regard to cardiovascular abnormalities. They were either teetotallers or consumed daily some alcoholic beverage, their habits thus providing a continuum of alcohol consumption from zero to $400 \mathrm{oz}$. of beer per day. The occupations of the 359 men who were studied are presented in Table I.

On the day of the initial interview each man was instructed to eat and drink as usual. Each subject had a complete physical examination and a full record was taken of his medical, social, and economic background. A chest $x$-ray and fluoroscopy of the chest for coronary artery calcification were done. Blood samples were taken for various biochemical and haematological investigations. Complete and detailed results of the latter will be reported elsewhere.

Diet. In an attempt to obtain some details of the eating and drinking habits of the subjects, each person

Received August 29, 1968.

* Supported in part by the Arnold Yeldham and Mary Raine Medical Research Foundation of the University of Western Australia and in part by the Research and Special Purposes Fund of the Royal Perth Hospital, Perth, Western Australia.

† Biostatistician to the University of Western Australia. was given a set of dietary forms to fill in for Thursday, Friday, and Sunday of the week after the interview. Instructions included with the forms set out the manner in which records were to be kept.

Electrocardiograms. The subject's electrocardiogram was recorded before and after walking on a treadmill at 3 m.p.h. at a 15 per cent gradient for a period of 10 minutes or less depending on the subject's discomfort. This type of exercise was chosen because walking represented a natural physical stress to the subjects, and the level of exercise was sufficient to increase the heart rate of all subjects to more than 100 beats a minute.

The system of classifying electrocardiograms, the "Minnesota Coding System", was that of Blackburn et al. (1960).

The electrocardiograms were reported on independently by two physicians, and differences in classification or coding were resolved by discussion.

The "Minnesota Coding System", though excellent for detecting clinical abnormalities, does not provide a metric suitable for correlation analysis, so the following scoring technique was devised.

Two physicians reported independently on each electrocardiogram. They were unaware of any details of the subject apart from his name and age. The basis of the reporting was clinical experience. Where a record was considered to be completely normal it was given a score of 9 . Where the physician "felt" there was a 10 per cent chance of the electrocardiogram being abnormal it was given a score of 8 , a 20 per cent chance of abnormality scored 7, and so on down to the "completely abnormal" one which scored 0 . For example, an electrocardiogram that had doubtful S-T segment flattening in lead $I$, or alternatively tall peaked $T$ waves in V1-V4 might be given a score of 7 or 8 depending on the reporter. An electrocardiogram showing small $Q$ waves in leads II, III, and aVF might be given a score of 6 by one observer and 8 by another. Widening of the QRS complex might be given a score of 7 by one observer and 9 by another. Obvious anterior myocardial infarction would attract 0 from all observers. Right bundle-branch block might attract 7 from one observer and 4 from another. 
TABLE I

DISTRIBUTION OF OCCUPATIONS AND DRINKING HABITS

\begin{tabular}{|c|c|c|c|c|c|}
\hline \multicolumn{3}{|c|}{ "White collar" workers } & \multicolumn{3}{|c|}{ Manual workers } \\
\hline . & Teetotal & Drinkers & & Teetotal & Drinkers \\
\hline $\begin{array}{l}\text { Business executives } \\
\text { Professional } \\
\text { Clerks } \\
\text { Salesmen } \\
\text { Liquor representatives } \\
\text { Hoteliers } \\
\text { Bookmakers }\end{array}$ & $\begin{array}{r}7 \\
5 \\
26 \\
11 \\
6 \\
-\end{array}$ & $\begin{array}{r}50 \\
20 \\
48 \\
41 \\
20 \\
36 \\
5\end{array}$ & $\begin{array}{l}\text { Tradesmen } \\
\text { Labourers } \\
\text { Barmen } \\
\text { Cellarmen }\end{array}$ & $\begin{array}{l}9 \\
6 \\
2\end{array}$ & $\begin{array}{r}38 \\
17 \\
6 \\
6\end{array}$ \\
\hline Total & 55 & 220 & Total & 17 & 67 \\
\hline Total teetotallers & \multicolumn{4}{|c|}{$\begin{array}{l}72 \\
\end{array}$} & \\
\hline Total drinkers & & \multicolumn{4}{|c|}{287} \\
\hline Over-all total & & \multicolumn{4}{|c|}{359} \\
\hline
\end{tabular}

The scoring of the electrocardiogram after effort was related to changes attributed to the effort and not to any abnormality in the resting tracing. For example, doubtful widening of the QRS at rest might attract a score of 8 . If this discrepancy were present in the postexercise tracing and no other abnormality appeared, the tracing would score 9.

Where there was only a slight discrepancy between the scores from the two physicians the average was taken. Where there was a gross discrepancy, a third physician reported on the electrocardiogram and an average of the three scores was taken.

Statistical analysis. All the information was punched on cards. Linear correlation and multiple regression techniques were used, the latter to determine those variables that exerted significant independent effects on selected dependent variables.

\section{RESULTS}

Alcohol Consumption and Smoking Habits. The drinking habits of the 359 subjects are seen in Tables II and III. These subjects were predominantly beer drinkers.

Table III shows the subdivision on the basis of daily beer consumption. This subdivision was made for the purpose of easy presentation of results.

TABLE II

ANALYSIS OF ALCOHOL CONSUMPTION

\begin{tabular}{l|r}
\multicolumn{1}{c|}{ Type of alcohol } & No. \\
\hline Teetotal & 72 \\
Beer only & 168 \\
Beer and wine (light and fortified) & 34 \\
Beer and spirits & 48 \\
Beer, spirits and wine (light and fortified) & 30 \\
Wine alone (light and fortified) or spirits alone & 7 \\
\hline & Total \\
\hline
\end{tabular}

Where the source of alcohol was not beer a conversion factor was used to express the amount of alcohol in terms of beer equivalent. This conversion factor was based on the percentage by volume of alcohol content: times 3 for light wine; times 5 for fortified wine; and times 10 for spirits. Western Australian beer contains approximately 4 per cent by volume of alcohol.*

TABLE III

DAILY ALCOHOL CONSUMPTION

\begin{tabular}{l|c}
\hline \multicolumn{1}{c|}{ Alcohol consumption } & No. \\
\hline Teetotal & 72 \\
Low-1 to 40 oz. beer or equivalent daily & 95 \\
Moderate-41 to 80 oz. beer or equivalent daily & 72 \\
High-81 to 150 oz. beer or equivalent daily & 54 \\
Very high-more than 150 oz. beer or equivalent daily & 66 \\
\hline Total & 359 \\
\hline
\end{tabular}

The smoking habits of the subjects are set out in Table IV. The smoking of manufactured cigarettes was the most common habit. There were very few pipe smokers.

Despite the close association between smoking and drinking habits, the multiple regression method shows significant and separate correlations of these factors with electrocardiographic abnormalities, increase in cardiothoracic ratio, etc.

The mean ages, heights, and weights of the various drinking groups are presented in Table V.

* Footnote: it also contains iron 0.19 parts/million, copper 0.03 parts/million, calcium $20-30$ parts/million, protein 0.05 g. $/ 100 \mathrm{ml}$., carbohydrate $4.00 \mathrm{~g} . / 100 \mathrm{ml}$., riboflavine 0.11 $\mathrm{mg} . / 100 \mathrm{ml}$., and niacin $1.1 \mathrm{mg} . / 100 \mathrm{ml}$. 
TABLE IV

SMOKING HABITS

\begin{tabular}{l|r}
\hline \multicolumn{1}{c|}{ Smoking habits } & No. \\
\hline Non-smoker & 104 \\
Manufactured cigarettes & 207 \\
Manufactured and "roll-your-own" cigarettes & 17 \\
Manufactured cigarettes and pipe & 5 \\
"Roll-your-own", cigarettes & 18 \\
"Roll-your-own" cigarettes and pipe & 2 \\
Pipe only & 6 \\
\hline & Total \\
\hline
\end{tabular}

TABLE V

MEAN AGE, HEIGHT, AND WEIGHT OF SUBJECTS IN EACH GROUP

\begin{tabular}{l|c|c|c}
\hline $\begin{array}{c}\text { Type of } \\
\text { drinker }\end{array}$ & $\begin{array}{c}\text { Mean age } \\
\text { (yr.) }\end{array}$ & $\begin{array}{c}\text { Mean height } \\
\text { (cm.) }\end{array}$ & $\begin{array}{c}\text { Mean weight } \\
\text { (kg.) }\end{array}$ \\
\hline Teetotal & 45 & 173 & 77 \\
Low & 45 & 177 & 79 \\
Moderate & 44 & 174 & 82 \\
High & 45 & 176 & 84 \\
Very high & 48 & 178 & 88 \\
\hline
\end{tabular}

TABLE VI

RESULTS OF ELECTROCARDIOGRAM SCORING SYSTEM

\begin{tabular}{c|c|c}
\hline Score & Before exercise & After exercise \\
\hline 9 & 208 & 261 \\
8 & 84 & 38 \\
7 & 33 & 20 \\
6 & 9 & 9 \\
5 & 9 & 9 \\
4 & 9 & 2 \\
3 & 3 & 2 \\
2 & 1 & 5 \\
1 & 2 & 5 \\
0 & 1 & 359 \\
\hline Total & 359 & \\
\hline
\end{tabular}

Note: Scoring of electrocardiogram after exercise is related to changes attributed to effort, not to any abnormality in resting tracing.

Electrocardiograms. The scores before and after exercise are set out in Table VI. Scores in the various drinking groups are presented in Table VII. The number of classifiable electrocardiographic abnormalities according to the "Minnesota Coding
TABLE VIII

NUMBER IN EACH GROUP WITH CLASSIFIABLE ABNORMALITIES AS DETECTED BY "MINNESOTA CODING SYSTEM"

\begin{tabular}{l|c|c}
\hline Group & $\begin{array}{c}\text { Total No. } \\
\text { in group }\end{array}$ & $\begin{array}{c}\text { No. with } \\
\text { abnormalities * }\end{array}$ \\
\cline { 2 - 3 } Teetotal & 72 & $10(14)$ \\
Low & 95 & $10(11)$ \\
Moderate & 72 & $25(35)$ \\
High & 54 & $13(24)$ \\
Very high & 66 & $18(27)$ \\
\hline
\end{tabular}

$\star$ Percentages are in parentheses.

System" in the several groups can be seen in Table VIII.

Table VII shows that the electrocardiographic abnormalities in the drinkers begin to increase in frequency in the 40-80 oz. of beer per day group.

Comparison of Tables VII and VIII shows that with increasing alcohol consumption there is both a rise in the number who scored less than 9 and in the number who had classifiable coding abnormalities.

The most common abnormality was left axis deviation more negative than $-30^{\circ}$, as described by Blackburn et al. (1960). There were 15 cases in the drinking groups and one in the non-drinking group (Table IX).

The electrocardiographic score at rest decreased with increase in cardiothoracic ratio $(p<0.001)$, age $(p<0.01)$, current beer consumption $(p<0.05)$, physical activity $(p<0.01)$, and loss of peripheral arterial pulsations in the lower limbs $(p<0.01)$. With the exception of cardiothoracic ratio these factors were each independently related to the electrocardiographic score at rest in the multiple regressions.

General physical activity was divided into four groups. The grade of physical activity did not correlate with alcohol consumption; it did, however, correlate inversely with electrocardiographic abnormality at rest, i.e. the greater the level of general physical activity the greater the likelihood of the cardiogram being abnormal.

TABLE VII

ELECTROCARDIOGRAM ABNORMALITIES AT REST-SCORING SYSTEM BEFORE EXERCISE

\begin{tabular}{|c|c|c|c|c|c|c|c|c|c|c|c|}
\hline \multirow{2}{*}{$\begin{array}{l}\text { Type of } \\
\text { drinker }\end{array}$} & \multirow{2}{*}{$\begin{array}{l}\text { Total } \\
\text { No. in } \\
\text { group }\end{array}$} & \multicolumn{10}{|c|}{ Score } \\
\hline & & 9 & 8 & 7 & 6 & 5 & 4 & 3 & 2 & 1 & 0 \\
\hline $\begin{array}{l}\text { Teetotal } \\
\text { Low } \\
\text { Moderate } \\
\text { High } \\
\text { Very high }\end{array}$ & $\begin{array}{l}72 \\
95 \\
72 \\
54 \\
66\end{array}$ & $\begin{array}{l}53(73) \\
59(62) \\
24(47) \\
28(52) \\
35(53)\end{array}$ & $\begin{array}{r}8(11) \\
24(25) \\
23(32) \\
14(26) \\
15(23)\end{array}$ & $\begin{array}{l}8(11) \\
5(5) \\
6(8) \\
6(11) \\
8(12)\end{array}$ & $\begin{array}{l}-1(-) \\
2(2) \\
1(1) \\
1(2) \\
5(8)\end{array}$ & $\begin{array}{l}3(4) \\
1 \text { (1) } \\
2 \text { (3) } \\
2(4) \\
1(2)\end{array}$ & $\begin{array}{l}-(-) \\
2(2) \\
5(7) \\
2(4) \\
-(-)\end{array}$ & $\begin{array}{l}-1(-) \\
1(1) \\
1(2) \\
-(-)\end{array}$ & $\begin{array}{l}=(\text { (二) } \\
=(\text { (二) } \\
=(\bar{l})\end{array}$ & $\begin{array}{l}1(1) \\
1(1) \\
\frac{1}{1}\left(\frac{(}{(2)}\right)\end{array}$ & $\begin{array}{l}1 \text { (1) } \\
=(\text { (二) } \\
=(\text { (二) }\end{array}$ \\
\hline
\end{tabular}

Percentages are in parentheses. 
TABLE IX

DETAILS OF 16 SUBJECTS WITH LEFT AXIS DEVIATION

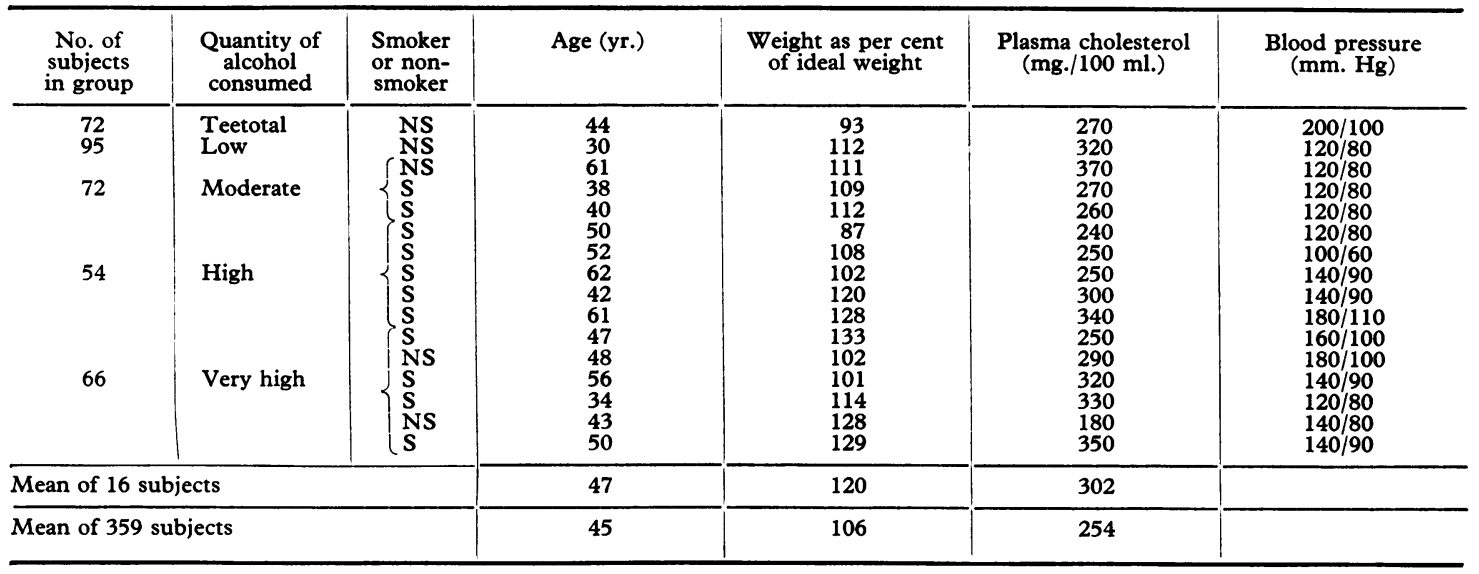

The electrocardiogram score after exercise decreased with increase in cardiothoracic ratio ( $p<$ $0.01)$, diastolic blood pressure $(\mathrm{p}<0.05)$, and with loss of peripheral arterial pulsations in the lower limbs $(\mathrm{p}<0.001)$. The multiple regression analysis showed that age, loss of peripheral pulses, and "total tobacco ever" were more closely related to changes in the electrocardiogram after exercise than other factors. There was no correlation between any of the measurements of alcohol consumption and the electrocardiographic score after exercise.

Increase in cardiothoracic ratio was found to correlate independently with increasing age, increase in systolic blood pressure, and "current" beer consumption $(p<0.05)$.

Diet. Intake of protein, iron, thiamine, vitamin A, riboflavine, and calories was expressed as a percentage of the subject's recommended intake (Nutrition Committee, National Health and Medical Research Council, 1965) which includes a correction for physical activity.

The daily intake of fat, carbohydrate, niacin, and vitamin $\mathrm{C}$ was also calculated.

There was no significant difference demonstrated between the five groups of varying alcohol consumption in respect of protein, fat, thiamine, iron, and riboflavine intake. Non-drinkers consumed more vitamin $A$ than drinkers. The mean consumption of vitamin A by all subjects, however, was well above the recommended 2500 International Units per day.

Heavy drinkers had a higher intake of niacin, though in no case was the niacin intake inadequate.

The thiamine intake of all groups was at a level similar to that found in the general population in Perth, i.e. mean about $0.25 \mathrm{mg}$. $/ 1000$ calories.
Though this falls short of the $0.4 \mathrm{mg}$. $/ 1000$ calories recommended by the Nutrition Committee, this committee also states that it cannot be concluded that the individuals are necessarily suffering from nutritional deficiency. "Dietary assessments are a very rough guide to the possible presence of nutritional deficiency disease" (E. H. Hipsley, 1968, personal communication).

The heavy drinkers consumed far less carbohydrate than the teetotallers but had a higher caloric intake due to their alcohol ingestion (Table $\mathrm{X}$ ).

Weight. The subject's weight was compared to his ideal weight (Wheatley and Stevens, 1955).

Only 5 per cent of all subjects weighed less than 90 per cent ideal weight; none weighed less than 75 per cent as calculated by Wheatley and Stevens (Fig.). Approximately 8 per cent were greater than 125 per cent ideal body weight. Increase in weight correlated independently with increase in cardiothoracic ratio, current beer consumption, maximum spirit consumption, increase in age, and increase in systolic blood pressure.

TABLE $X$

DIETARY INTAKE OF CARBOHYDRATES, CALORIES, AND THIAMINE

\begin{tabular}{l|c|c|c}
\hline Group & $\begin{array}{c}\text { Mean carbo- } \\
\text { hydrate } \\
\text { intake } \\
\text { (g./day) }\end{array}$ & $\begin{array}{c}\text { Mean caloric } \\
\text { intake as per } \\
\text { cent of } \\
\text { subject's } \\
\text { recommended } \\
\text { daily intake }\end{array}$ & $\begin{array}{c}\text { Mean thiamine } \\
\text { intake } \\
\text { expressed as } \\
\text { per cent of } \\
\text { recommended } \\
\text { daily intake }\end{array}$ \\
\hline Teetotal & 315 & 95 & 71 \\
Low & 240 & 92 & 72 \\
Moderate & 212 & 92 & 67 \\
High & 175 & 102 & 66 \\
Very high & 170 & 18 & 66 \\
\hline
\end{tabular}




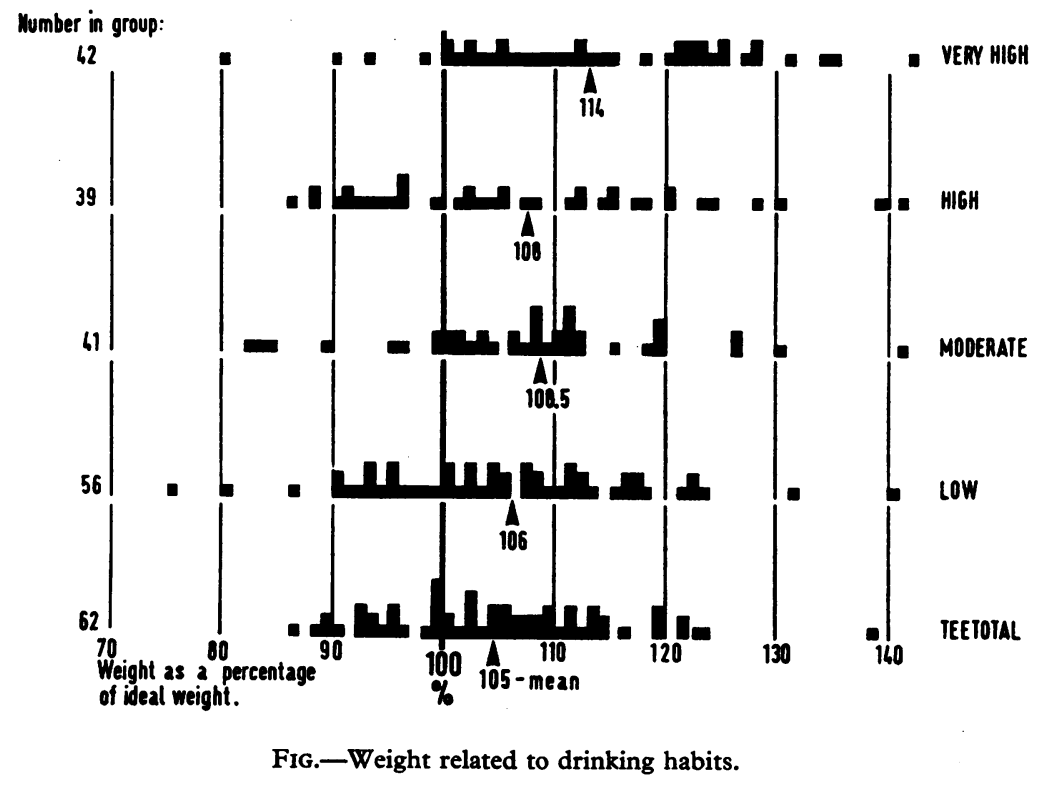

Biochemical Findings. Plasma cholesterol levels were related statistically to weight and deterioration in the electrocardiogram after exercise.

Decrease in serum carotene was related to most measurements of beer and cigarette consumption but particularly to "current" beer and "total current" alcohol consumption ( $p<0.001)$.

\section{Discussion}

Validity of Sampling Procedure. This is not a random sample of the Perth population.

Though the drinking habits of the population as a whole are unknown, it may be assumed that our sample included a larger proportion of medium, high, and very high drinkers than that seen in the normal population.

Subjects with previously recognized heart disease were excluded.

In an investigation where volunteers are aware that the main interest of the study is the cardiovascular system, there will obviously be a tendency for persons who are "heart conscious" to take part. This may increase the incidence of heart disease in the group as a whole. We do not believe that these motives vary with alcohol or tobacco consumption.

A psychological bias could well be present. It seems reasonable to assume that a person who has spent most of his life consuming quite large quantities of alcohol has a different personality from a complete abstainer. Whether fundamental personality factors could have a beneficial or deleterious effect on cardiovascular function is conjectural; it could be of considerable importance.

Validity of Scoring System. When dealing with a "normal" population one expects to find normal electrocardiograms. Some tracings deviate slightly from one's accepted normal standards. In these instances, as a result of years of clinical experience, doctors build up an ability to predict the chances of a particular tracing being normal. This experience has been put to practical use in this method which recognized the essentially subjective nature of much electrocardiographic interpretation.

There is also a certain safety in having three independent reports.

At all times it must be acknowledged that the electrocardiogram is only a crude guide to myocardial structure and functure.

Assessment of Alcohol and Tobacco Consumption. The fact that the subjects were volunteers who were aware that the study was concerned with alcohol and its effect on the body suggests that they would be willing to give an accurate account of their drinking and smoking habits. That these men should volunteer for such a study suggests that their personalities are relatively uninhibited and that they are not seeking to minimize their habits.

Allowing for the assumption that the subjects were co-operating to the best of their ability, it must still be acknowledged that we are entirely dependent on their ability to recall their habits over a period of 
years. Todd (1966) studied a group of men in 1954 and documented their smoking habits at that time. $\mathrm{He}$ interviewed the subjects a second time in 1964 and asked them to recall their smoking habits of 1954. The lack of correlation between the two sets of figures was extreme in many cases and illustrates the difficulty in obtaining reliable figures from subjective assessment.

To overcome this difficulty we have included several measures of alcohol and tobacco consumption such as "current", "maximum", and "average". A person who drinks $100 \mathrm{oz}$. of beer a day for 5 years has consumed the same total volume of beer as a man who drinks $50 \mathrm{oz}$. of beer a day for 10 years. It is impossible to say whether or not this total volume of alcohol can be considered to have similar effects. Another type of difficulty is illustrated by a person who has been a heavy drinker for 20 years, and has become a light drinker for the past four years. Therefore, it seemed reasonable to study alcohol and tobacco by as many different measures as possible.

Of these measures, the "current" consumption of the various forms of alcoholic drink, the one which is likely to be the most accurate of the various measurements, was more closely related to cardiovascular abnormalities than "maximum" or "average" measures of drinking habits.

Validity of Diet History. It is notoriously difficult to obtain a satisfactory dietary history.

Diet sheets were analysed only from subjects who recorded their diets quantitatively; it was realized that their food quantities might be inaccurate. Such vague terms as "large helping of steak" rendered a history unsuitable. This difficulty and the failure to return records resulted in only 250 out of a possible 359 records being available for analysis.

Despite these factors the authors believe the information obtained is close to the truth.

Cause of Electrocardiographic Abnormalities. The association of current beer consumption with deterioration in the cardiogram at rest and increase in the cardiothoracic ratio may reflect in part some of the following factors.

(1) Alcoholic cardiomyopathy. Alcohol is often cited as a cause of heart disease (Ferrans, 1966). Alexander (1967) showed that electron microscopical studies of myocardial biopsies from 100 subjects suspected of alcoholic heart disease revealed gross myocardial damage.

The amount of alcohol consumed by some of our subjects is comparable with the intake of some chronic alcoholics (Rankin et al., 1966).
Of the range of distinctive electrocardiographic changes described by Evans (1961), only the S2S3 pattern which reflects abnormal left axis deviation was seen to be characteristic of the drinkers in our series.

Recent studies (Eliot, Millhon, and Millhon, 1963; Corne et al., 1965) indicate that left axis deviation reflects general myocardial damage of some degree and may result from myocardial fibrosis, recent cardiac infarction, various types of cardiomyopathy, congenital defects, left ventricular hypertrophy, pulmonary emphysema, and ischaemia of the left ventricular conducting system. In a minority there is no clinical or pathological evidence of heart disease.

We do not think the electrocardiographic abnormalities recorded were related to high blood alcohol levels at the time of testing.

Blood alcohol estimates were not made, as results on 20 subjects in a pilot study were below the lower limits of accuracy as measured by the Conway Unit Microdiffusion Technique (Williams, Linn, and Zak, 1958).

Whether the minor deviations from normal in the electrocardiograms of the drinkers would revert to normal when they ceased regular drinking is a question that cannot be answered from this study. Correlation of the abnormality at rest with "current" alcohol consumption suggests that this is a possibility.

The significant relation between increase in the general level of physical activity and electrocardiographic abnormality at rest in a drinking population may be related to the findings of Elson and Abelmann (1965) who showed an increased severity of Chagas myocarditis in rats that were exercised compared with unexercised controls.

(2) Coronary atherosclerosis. Atherosclerosis of the coronary arteries is a possible cause of the cardiac changes observed with increased alcohol consumption in these subjects.

Classical angina and atypical chest pain were absent because of the method of selection of the subjects. There was no correlation between beer consumption and electrocardiographic changes after exercise, which suggests that coronary artery disease is not a causative factor.

Another argument against coronary atherosclerosis being a major cause of the electrocardiographic abnormalities observed is the absence of a correlation between alcohol consumption and coronary artery calcification as detected by image intensifier screening.

Serum cholesterol levels did not correlate with the electrocardiogram or cardiothoracic abnormalities, 
which is another argument against coronary artery disease being responsible for the cardiovascular abnormalities.

(3) Hypertension. Systolic hypertension may be contributing to the increased cardiothoracic ratio of the drinkers, but there was no correlation between electrocardiographic abnormality and systolic or diastolic hypertension.

(4) High output states associated with cirrhosis of the liver. There was no clinical evidence of cirrhosis of the liver. There was no correlation between liver function tests and electrocardiographic abnormality and cardiothoracic ratio changes.

Granted that cirrhosis can be shown to be present by liver biopsy in the presence of normal biochemical findings, it is conceivable, but unlikely, that a high output state associated with cirrhosis of the liver was causing electrocardiographic and cardiothoracic abnormalities.

(5) Increase in weight. Increase in weight does not appear in the statistical analysis of factors affecting the electrocardiographic score, and is therefore unlikely as a cause of the changes in this survey. However, increase in the weight could be a cause of the increase in cardiothoracic ratio.

(6) Nutritional deficiency. Despite their wellnourished appearance it is possible that subjects suffered from malabsorption of a substance such as thiamine. Evidence obtained from the dietary analysis did not reveal any dietary deficiency apart from low thiamine intake which was apparent in all groups.

This finding agrees with the experience of the Dietary Department of Royal Perth Hospital who record similar levels in most normal diets in Perth.

A study of the digestive system of "skid row" alcoholics at the termination of a drinking episode revealed varying degrees of physiological disturbance of one or more of the digestive organs (Small, Longarini, and Zamcheck, 1959).

The low serum carotene, which was a striking finding in the heavier drinkers, indicates some degree of malabsorption and deserves further study.

In summary, the weight of evidence, at present, favours the view that it is more likely that alcohol acts directly on the heart causing cardiomyopathy rather than indirectly by causing coronary atherosclerosis, hypertension, high output states, obesity, nutritional deficiency, or myocardial haemosiderosis.

Smoking. The measurement "total ever" tobacco is associated with deterioration in the electro- cardiogram after exercise and increase in the cardiothoracic ratio in the multiple regression analysis. These correlations add to the extensive published reports linking smoking with heart disease.

\section{SUMMARY}

Though the association of heart disease with the chronic alcoholic is well known, little is known about the incidence of heart disease in well and working social drinkers.

This statistical study of 359 well and working men, whose daily drinking habits range from being teetotal to drinking $400 \mathrm{oz}$. of beer or its equivalent, has shown that when the regular daily intake of beer of a man in Perth, Western Australia, is of the order of 40-80 oz. or more he can expect to have a higher incidence of electrocardiographic abnormality, as detailed by the "Minnesota Coding System" and by a scoring system based on the clinical experience of three physicians. The most common abnormality was left axis deviation more negative than $-30^{\circ}$.

This study has not been able to demonstrate that alcohol itself damages the myocardium.

Deterioration of the resting electrocardiogram with an increasing general level of daily physical activity was an interesting finding.

The association of resting electrocardiogram abnormality with "current" beer consumption rather than other measurements of alcohol consumption leaves the possibility that these electrocardiographic changes may be reversible.

Multiple regression analysis showed that "current" beer consumption was related to increase in the cardiothoracic ratio, as were age, systolic blood pressure, "maximum" spirit consumption, weight, and "total ever" tobacco.

The measurement "total ever" tobacco was related to abnormalities in the electrocardiogram after exercise.

The authors express thanks to The Arnold Yeldham and Mary Raine Medical Research Foundation for financial assistance; The Research and Special Purposes Fund of Royal Perth Hospital for financial assistance; the Departments of Radiology, Biochemistry, Haematology, Dietetics and Medical Illustrations, Royal Perth Hospital for assistance; Dr. T. B. Cullity, Professor D. Curnow, Dr. B. F. Vaughan, Dr. J. Varey, and Dr. G. N. Cumpston for advice and assistance; the technical staff of the Department of Cardiology, Royal Perth Hospital for enthusiastic help; and Miss Wiseman for secretarial assistance.

\section{REFERENCES}

Alexander, C. S. (1967). Electron microscopic observations in alcoholic heart disease. Brit. Heart f., 29, 200. 
Blackburn, H., Keys, A., Simonson, E., Rautahariu, P., and Punsar, S. (1960). The electrocardiogram in population studies. A classification system. Circulation, 21, 1160.

Corne, R. A., Parkin, T. W., Brandenburg, R. O., and Brown, A. L. (1965). Significance of marked left axis deviation; electrocardiographic-pathologic correlative study. Amer. F. Cardiol., 15, 605.

Eliot, R. S., Millhon, W. A., and Millhon, J. (1963). The clinical significance of uncomplicated marked left axis deviation in men without known disease. Amer. $\mathcal{F}$. Cardiol., 12, 767.

Elson, S. H., and Abelmann, W. H. (1965). Effects of muscular activity upon the acute myocarditis of $\mathrm{C} 3 \mathrm{H}$ mice infected with Trypanosoma cruzi. Amer. Heart f., 69, 629.

Evans, W. (1961). Alcoholic cardiomyopathy. Amer. Heart F., 61, 556.

Ferrans, V. J. (1966). Alcoholic cardiomyopathy. Amer. F. med. Sci., 252, 89.

Nutrition Committee, National Health and Medical Research Council (1965). Dietary Allowances for Australians, p. 7. Canberra.

Rankin, J. G., Santamaria, J. N., O'Day, D. M., and Doyle, M. (1966). The natural history, treatment and prognosis of alcoholism. Aust. Ann. Med., 15, 374.

Small, M., Longarini, A., and Zamcheck, N. (1959). Disturbances of digestive physiology following acute drinking episodes in "skid-row" alcoholics. Amer. F. Med., 27, 575.

Todd, G. F. (1966). Reliability of statements about smoking habits. Suppl. Report. Tobacco Research Council, London. Research Paper 2A.
Wheatley, A. W. R., and Stevens, C. J. (1955). Assessment of risks: build. Fifty-ninth session, Actuarial Society of Australasia. Transactions, 9, 93.

Williams, L. A., Linn, R. A., and Zak, B. (1958). Determination of ethanol in fingertip quantities of blood. Clin. chim. Acta, 3, 169.

\section{ADDENDUM}

Y. Morin, J-L. Bonenfant, G. Miller, and J-L. Beaudoin presented a paper entitled "Une épidemie de cardiomyopathie chez des buveurs de bière" at the 5th European Congress of Cardiology, 1968. They discussed 48 cases of an epidemic cardiomyopathy attributed to beer containing 1.2 parts/million of cobalt. The October 7 , 1967, issue of The Canadian Medical Association fournal, 97, No. 15, which is entitled Quebec Beer Drinkers' Cardiomyopathy, contains a detailed summary of this work.

We have good reason to believe that at the time of the Perth survey some Western Australian beer contained $0.4-0.8 \mathrm{parts} /$ million of cobalt, in contrast to most other Australian beers whose cobalt content was about 0.003 parts/million. Western Australian beer now also contains 0.003 parts/million of cobalt. Further, it cannot be ascertained for what period Western Australian beer contained the higher cobalt level.

Cobalt toxicity might well be a factor contributing to the association we found between "current" beer consumption, and both increase in cardiothoracic ratio and increase in resting electrocardiographic abnormalities. 